\title{
Função do Diretor na Escola Pública Paulista: mudanças e permanências
}

\author{
Graziela Zambão Abdian' \\ Maria Eliza Nogueira Oliveira' \\ Graziela de Jesus' \\ 'Universidade Estadual Paulista (UNESP), Marília/SP - Brasil
}

\begin{abstract}
RESUMO - Função do Diretor na Escola Pública Paulista: mudanças e permanências. Com este estudo, pretende-se analisar a função do diretor na escola estadual paulista, à luz das concepções dos especialistas da Administração Escolar, da percepção dos profissionais da Educação e das diretrizes legais pertinentes ao governo estadual. Neste contexto, interessam os procedimentos de releitura e análise da literatura da área; o levantamento e análise de documentos legais que, direta ou indiretamente, referem-se à função do diretor de escola e a realização, transcrição e análise de entrevistas semielaboradas com gestores e equipes de docentes. Os resultados da análise indicam contradições na percepção da Administração Escolar, tal como difusa nos diferentes âmbitos que, de certa forma, refletem-se nas concepções dos entrevistados.

Palavras-chave: Diretor de Escola. Política Educacional. Organização do Trabalho na Escola.
\end{abstract}

ABSTRACT - The Duties of the Principal in São Paulo State Schools: changes and continuities. This essay is intended for an analysis of the principal's duties in São Paulo State school, considering the conceptions of Administration specialists, Education professionals and the legal directives pertinent to the State government. It was interesting the procedures of rereading and analyzing of the literature of the area; the survey and analysis of legal documents which, direct or indirectly, concern the principal's duty and the accomplishment, transcription and analysis of half elaborated interviews with administrators and teachers. At the end of this research, it was found some contradictions in the conception of School Administration like it is diffused in different contexts, which anyway reflects the conceptions of the respondents.

Keywords: Principal's Duties. Educational Policy. Organization of Working as School.

Educação \& Realidade, Porto Alegre, v. 38, n. 3, p. 977-998, jul./set. 2013. 


\section{Introdução}

Este artigo origina-se de trabalho com dados de pesquisa apoiada pela Fundação de Amparo à Pesquisa do Estado de São Paulo (FAPESP, 2008-2010) e também de subprojeto de pesquisa apoiado pelo Observatório de Educação (CAPES/INEP, Edital n. 38/2010), vinculados ao Centro de Estudos e Pesquisas em Administração da Educação (CEPAE), visando aos objetivos principais a seguir: a) analisar questões históricas e atuais relacionadas à formação, função e provimento do cargo do gestor escolar e suas possíveis implicações na qualidade de ensino da escola pública; b) problematizar a literatura da área concernente às temáticas articuladas, cotejando-a com as propostas e práticas de Gestão da Educação. A pesquisa envolveu vários subprojetos com temáticas integradas ao objetivo principal e utilizou diferentes procedimentos de coleta de dados, entre os quais a análise de provas e editais de concurso para diretores de escola do Estado de São Paulo; análise de documentos; entrevistas semielaboradas com gestores e docentes de escolas públicas, municipais e estaduais.

Este artigo se propõe a analisar a função do diretor de escola estadual paulista, confrontando-a com as concepções dos autores da Administração Escolar, dos profissionais da Educação (equipe de gestão e docentes) e das diretrizes legais do governo estadual. Como procedimentos, utilizou-se da releitura e análise da literatura de clássicos da área, levantamento e análise de documentos legais que se referem, direta ou indiretamente, à função do diretor de escola e a realização, transcrição e análise de entrevistas semielaboradas com gestores e equipes de docentes de escolas públicas estaduais de município no interior do Estado de São Paulo. A gênese da proposta implica as reflexões que vêm sendo consolidadas no âmbito do CEPAE, a partir de encontros, discussões, revisões e mudanças de perspectivas que, de certa forma, favorecem algumas ideias balizadoras, a saber: é preciso considerar a produção do conhecimento para se levantarem novas inferências a respeito de objetos de estudo (Russo, 2004); os sujeitos da prática - aqueles que estão diretamente implicados no fazer cotidiano dos sistemas e das escolas - apresentam conhecimentos valiosos que precisam ser valorizados (Alves; Garcia, 2003); a análise da gestão escolar, com suas subtemáticas, torna-se mais complexa, se considerar-se intencionalmente as produções do conhecimento oriundas da academia, da escola e no âmbito das diretrizes políticas.

Abordar especificamente a função do diretor de escola a partir dessas ideias balizadoras não é tarefa simples por diversas razões, entre as quais duas merecem destaque: não é assunto recente na área da gestão escolar (Teixeira, 1997; Ribeiro, 1952; Ribeiro, 1968); esteve (e está) articulado com outras temáticas, como as relacionadas à formação desse profissional e à forma de provimento do seu cargo. Ademais, dependente ou independentemente dos avanços teóricos da área, a julgar 
pela política educacional que, ao longo das últimas décadas, delineia diretrizes de descentralização e concessão de autonomia aos entes federados, identificam-se práticas bastante diferenciadas de exercício da função do diretor de escola: umas mais próximas dos avanços teóricos - o que será trabalhado neste estudo -, outras se aproximando de concepções mais tradicionais da função do diretor de escola.

Particularmente no Estado de São Paulo, as diretrizes da política educacional, que já foram analisadas e criticadas por diferentes autores (Fonseca, 1997; Krawczyk, 2008; Oliveira, 2002), consolidam-se e delineiam a presença de um diretor - líder e empreendedor, no sentido empresarial -, com o propósito de melhorar os resultados nos exames nacionais e estaduais. Concomitante e contraditoriamente a tais diretrizes, preconizam-se a participação e a autonomia da escola, a gestão democrática com a presença de órgãos colegiados atuantes desde os anos 1980 (São Paulo, 1985).

Para que fosse cumprido satisfatoriamente o objetivo proposto, segmentou-se o texto em três partes, seguidas das considerações finais. Primeiramente, faz-se uma incursão na produção do conhecimento, considerando autores clássicos dos anos 1960 aos anos 2000 para, em seguida, proceder-se a um recorte da legislação paulista. Analisam-se, ao longo das décadas de 1980 e 2000, as concepções a respeito da função do diretor de escola. Na terceira parte, consideram-se as entrevistas realizadas com quatro diretores de escolas em regiões diferentes do município paulista, e com as equipes docentes destas escolas. Por fim, visam-se os três âmbitos - conhecimento da área, profissionais da educação, legislação - e manifestam-se algumas reflexões acerca do presente trabalho.

\section{A Função do Diretor de Escola Concebida por Autores Clássicos da Administração Escolar}

Possivelmente, uma das mais complexas discussões a respeito da Escola refere-se à sua administração/gestão, sobremaneira se referindo a como ou quem deve estar à frente da tomada de decisões que envolve toda a organização pedagógica e burocrática.

Nas décadas de 1960 e 1970, boa parte dos estudos em Administração Escolar (Ribeiro, 1968; Lourenço Filho, 2007; Alonso, 1976) subsidiou-se na Teoria Geral da Administração (TGA) - cujo pressuposto jazia na afirmação de que administrar uma escola equivale a administrar uma empresa qualquer -, com o intuito de assegurar a eficiência e eficácia do empreendimento escolar.

Compartilhando do princípio da TGA, Ribeiro (1968,) sugere que a Administração seja meio e não fim em si mesma e que ela se fundamenta em três elementos que têm em vista a complexidade dos empreendimentos humanos e o jogo de interesses daí advindos: racionalização do trabalho; divisão do trabalho e interesse no trato pela Administração. 
Concebe-se a Administração uma solução aos riscos causados pela divisão do trabalho. Com efeito, chega a definir-se como o processo para melhor conduzir os grupos humanos que operam em tarefas divididas para alcançar um objetivo comum.

Em sintonia com Ribeiro (1968), Lourenço Filho (2007) ${ }^{1}$ indica que a função do diretor/administrador escolar concentra-se na liderança. No que tange às atividades do administrador, devem-se considerar a de coligir informações de problemas e a de decidir a resolução dos problemas. Para tanto, cabe ao administrador conhecer o empreendimento em que está inserido para, posteriormente, atuar, acrescentando questões, a saber: onde, quando, como operar em cada caso. Quatro modalidades traduzem essa ação administrativa: a) planejar e programar; b) dirigir e coordenar; c) comunicar e inspecionar; d) controlar e pesquisar.

O autor elucida que planejar significa figurar, em termos simbólicos, o que deve ser realizado, em termos de qualidade e quantidade; programaré estabelecer objetivos graduais que permitam a consecução do resultado pretendido. Já as ações de dirigir e coordenar consistem em fazer funcionar, na devida forma e tempo - o que implica a divisão de tarefas e a consequente demarcação de esferas de responsabilidades e de níveis de autoridade.

Lourenço Filho (2007) enfatiza a importância da comunicação, porque, segundo ele, muitos problemas são fruto da falta de informação, tanto por parte dos dirigentes quanto por parte dos subordinados. Inspecionar não significa apenas fiscalizar, no sentido de disciplinar, senão comunicar em todos os sentidos: de cima para baixo e de baixo para cima, favorecendo, pois, a maior solidariedade entre os que trabalham.

Dessa maneira, as atividades do administrador contempladas por Lourenço Filho (2007, p. 87) - coligir informações, planejar e programar, dirigir e coordenar, comunicar e inspecionar, controlar e pesquisar - contribuem para que equipes gestoras de qualquer escola alcancem os fins propostos e, consequentemente, possam cumprir o papel que se lhes predefiniu: “[...] produzir serviços de desenvolvimento e ajustamento social”. Complementando sua abordagem, Lourenço Filho (2007) acrescenta que a função de direção sempre se individualiza, razão por que, já na década de 1960, havia uma preocupação latente com seus atributos pessoais, uma vez que a liderança, para ele, referia-se à qualidade do administrador em bem interpretar o "[...] espírito comum da organização, optando e decidindo no melhor sentido de sua coesão” (Lourenço Filho, 2007, p. 78).

Uma década depois, Alonso (1976) trabalhou com abordagem semelhante, mas acrescentou resultados de pesquisas empreendidas em outros países. Adotou os princípios da Teoria Geral dos Sistemas para a análise da organização escolar e propôs que a Administração escolar 
tenha como função o ajustamento dos fatores internos e externos do sistema escolar, para que se mantenha em equilíbrio.

Conquanto inclua outros elementos - representados pela análise de sistemas e pela contribuição da Psicologia -, a autora identifica a direção a um dos componentes do processo administrativo e "[...] representa um ponto muito importante uma vez que dela depende o funcionamento da engrenagem administrativa prevista nas fases anteriores do processo, dela dependendo, portanto, o funcionamento da empresa" (Alonso, 1976, p. 131).

Para tanto, admite que o papel do diretor seja fundamental para assegurar a unidade e a implementação de todo o programa institucional. Ademais, o diretor deve ser um líder do corpo docente, a ponto de estabelecer a tônica do processo educacional global, de transmitir entusiasmo e interesse pelo progresso do ensino e estimular o trabalho de equipes. Nesse sentido, a autora sugere que o diretor deva atuar junto aos vários especialistas, criando situações favoráveis ao trabalho de equipes, unindo esforços para desenvolver novos projetos e mantendo atualizados os professores, além de saber localizar os pontos fracos do sistema e de propor soluções convenientes (Alonso, 1976).

Para Alonso (1976), cabe ao administrador influenciar os vários níveis da organização escolar, ser influente na tomada de decisões e, ante os órgãos superiores da administração do ensino, justificar suas proposições, deles trazer informações, decisões necessárias à vida escolar, interpretá-las dentro de seu contexto e tentar aplicá-las em consonância com os seus colaboradores. Por conseguinte, a função do diretor e/ou administrador escolar “[...] não é mais uma função logística, isto é, de mobilização de recursos, mas sim uma função estratégica, ou seja, de condicionador de reações daqueles que serão afetados por certos objetivos e ações" (Alonso, 1976, p. 154).

Em contrapartida, na década de 1960, quando se instituiu a Associação Nacional de Política e Administração da Educação (ANPAE), em diálogo com Ribeiro (1968), Anísio Teixeira (1968) defendeu que a Administração escolar jamais poderia se equiparar à administração de empresas e atribuiu ao administrador escolar a função de mediadorinovador, ponderando que “[...] se alguma vez a função de direção faz-se uma função de serviço e não de mando, esse é o caso do administrador escolar" (Teixeira, 1968, p. 14).

Posto houvesse essa perspectiva, entre as décadas de 1960 e 1970 predominou a abordagem que nivelava empresa à escola, e o administrador escolar ao administrador de empresas, de forma que a função de direção se individualiza, e, ao diretor da organização escolar, atribui-se uma função de liderança e de responsabilidade pela “[...] prosperidade do empreendimento" (Ribeiro, 1968, p. 38)².

A década de 1980 marcou-se da crítica à construção teórica anterior, por haver equiparado a escola à empresa e adotado a TGA no de-

Educação \& Realidade, Porto Alegre, v. 38, n. 3, p. 977-998, jul./set. 2013.

Disponível em: <http://www.ufrgs.br/edu_realidade> 
Função do Diretor na Escola Pública Paulista

senvolvimento teórico da Administração Escolar. Pode-se considerar o estudo de Paro (1986) o propulsor desse período, por haver destacado, entre outros aspectos de grande relevância e rigor científicos, a especificidade da Administração escolar como um dos pressupostos para a transformação social.

Paro (1986) reflete a respeito de três aspectos presentes no processo de produção pedagógico que lhe atribuem natureza específica: o educando, o saber e o produto da educação. Segundo o autor, em Educação, o produto não pode ser separado do ato da produção, a ponto de que o aluno seja considerado coprodutor de todo o processo educativo. Por sua vez, o saber não é expropriado do processo de produção (do educando e do educador), o que o distancia do processo de produção da empresa, onde operários apenas produzem partes de uma mercadoria, sem compreender o conhecimento que envolve o seu trabalho.

O produto da Educação - afirma Paro (1986) - permanece além do ato da produção, ou seja, não é possível mensurar e/ou quantificar o conhecimento que produz, porquanto o saber é subjetivo, e a avaliação do conhecimento de uma pessoa abrange apenas um tipo de conhecimento específico.

Em se tratando da especificidade do processo de produção pedagógico, Paro (1986) defende a construção teórica sui generis da Administração Escolar: sobremaneira considerando os objetivos que se pretende alcançar por meio da escola e a natureza do processo que envolve o processo de busca. Para tanto, defende que a Administração deva ser fruto da coordenação do esforço humano coletivo, e não de indivíduos a quem se reservam poder e autoridade irrestrita sobre os demais.

Desse modo, supõe-se que a Administração escolar deveria se direcionar à democratização da sociedade e à sua especificidade, favorecendo aos sujeitos sociais estabelecer novos padrões de racionalização do trabalho e a aproveitar os espaços e possibilidades que o atual contexto lhes oferece.

Conquanto Paro (1986) não contemple explicitamente a discussão em torno da função do diretor escolar, tampouco se valha do referencial teórico adotado pelos estudos anteriores (Alonso, 1976; Lourenço Filho, 2007), ele parece indicar que a função do diretor seja a de mobilizar o grupo na luta pela democratização da sociedade e por uma administração/direção coletiva. Neste sentido, enfatiza-se o caráter político da função, à contracorrente do que ocorreu nas décadas anteriores, quando se supervalorizou a função técnica do diretor de escola.

Na década de 1990, paralelamente ao movimento que incentiva os estudos concernentes à escola (Nóvoa, 1995; Canário, 1996; Silva Jr., 2002), é possível identificar a coexistência de perspectivas diferentes, até divergentes, acerca da Administração escolar e da função do diretor escolar. Os autores Freire (1991) e Mello (1993) podem corroborar a expressão da assertiva. 
Freire (1991) defendeu a escola popular e democrática, séria e alegre. Sugeriu a proposta de educação que caminhasse para o despertar da consciência, visando à transformação social. Talvez a mais importante de suas ações tenha sido a luta pela implantação dos conselhos de escola, definidos como instituto “[...] responsável pela direção da Escola e pelas decisões que são tomadas” (SME, 1992 apud Lima, 2007, p. 61). Na visão de Freire (2000), para que o conselho de escola efetivamente funcionasse, seria imprescindível não apenas implementar a lei senão também favorecer experiências e condições para seu desenvolvimento, florescência, frutificação. Assim incorporada ao cotidiano das escolas, a gestão democrática teria vida mais intensa, o que abriria caminho para o entusiasmo entre todos os envolvidos no processo educacional.

Ao abordar o pensamento e ação de Freire (1991), Lima (2007) acentua questões específicas do diretor de escola, entre as quais a de que a Administração não pode, isoladamente, resolver todos os problemas da Educação. Não obstante, pode ser uma ferramenta de democratização da escola e da sociedade. Lima (2007) propõe que o “[...] diretor da unidade escolar, exercendo uma liderança democrática e criativa, seja capaz de promover a diferença, transformando a escola em um ambiente sério, porém alegre, prazeroso, bonito e saudável" (Lima, 2007, p. 53). Posto que apenas em parte se concorde com a postura de Lima (2007), uma vez que não se apreendem, na obra de Freire, os aspectos relacionados à liderança, podemos indicar, com a autora, que a função do diretor de escola, na perspectiva de Freire (1991), não se individualiza. Ao contrário, a escola é vista de forma complexa, na medida em que favorece a participação de todos na tomada de decisão.

Em contraposição a Freire (1991), Mello (1993) contempla as dez opções de política consideradas necessárias para a reviravolta na educação brasileira, provocando melhoria de qualidade e a consequente inserção do país no âmbito competitivo internacional. Entre essas opções, enfatiza-se a qualificação da gestão escolar que, para a autora, caracteriza-se como processo de diagnóstico, avaliação e definição de objetivos de desenvolvimento institucional, o que deveria abranger toda a equipe.

A autora sugere que a divisão do trabalho escolar seja efetivada por meio da definição de Plano de Desenvolvimento, comparável a um contrato a ser cumprido, a partir do qual a escola estaria em contínua prestação de contas, “[...] baseada tanto na auto-avaliação institucional como na avaliação da aprendizagem dos alunos, aferida por um sistema externo à escola" (Mello, 1993, p. 100).

Para isso, é imprescindível imprimir robustez à função do diretor escolar, favorecendo

[...] seu treinamento para exercer uma liderança democrática e responsável, sua autoconfiança e conhecimentos técnicos, vão constituir o melhor ponto de partida.

Educação \& Realidade, Porto Alegre, v. 38, n. 3, p. 977-998, jul./set. 2013.

Disponível em: <http://www.ufrgs.br/edu_realidade> 
Estrategicamente, é pela função do diretor que será mais provável ter sucesso para induzir a escola como um todo a engajar-se num processo de construção de identidade institucional que resulte num projeto de trabalho compartilhado (Mello, 1993, p. 97, grifo nosso).

O discurso de Mello (1993) ampara-se nas reformas educacionais em âmbito internacional, na medida em que defende o investimento na educação como um dos principais quesitos de inserção do país no mundo competitivo. Dessa maneira, harmoniza-se com a perspectiva empresarial de escola fundada em "[...] novo padrão de gestão", que busca, sobremaneira, parcerias com o setor empresarial. Nesse sentido, além de considerar as concepções várias a respeito da escola e de sua administração/gestão, importa perceber contradições internas em uma mesma abordagem. No texto de Mello (1993), identificam-se termos e conceitos empresariais como liderança e, paralelamente, há termos como gestão democrática, participação, autonomia da escola que, de certa forma, contrapõem-se àquela perspectiva empresarial de escola. Isso é sintomático de que a abordagem da administração/gestão escolar, sobretudo a partir do final dos anos 1980, processa-se de forma integrada às questões do contexto (forças divergentes, contradições, conflitos, poder), no sentido contraposto ao que ocorria nas décadas anteriores, e que, independentemente de seus subsídios teóricos, traçaram teorias normativas e generalizáveis. Conquanto não se compartilhe absolutamente da abordagem de Mello (1993), há de considerar a potencialidade de suas ideias no sentido de subsidiar material rico para discussão e compreensão da função do diretor de escola no real contexto escolar, com suas contradições, conquistas e retrocessos.

No final da década de 1990 e início dos anos 2000, Lück (2000, p. 13), discutindo a função do diretor escolar, explicita a necessidade de superar-se o modelo hegemônico de Administração escolar pautado na figura de um "[...] diretor tutelado dos órgãos centrais, sem voz própria, em seu estabelecimento de ensino, para determinar os seus destinos e, em consequência, desresponsabilizado dos resultados de suas ações e respectivos resultados".

Ao propor um novo olhar para as práticas do diretor escolar, a autora procede à discussão a respeito da mudança terminológica da área - administração escolar para gestão escolar -, porquanto, segundo ela, tal mudança traz consigo

[...] uma fundamental alteração de atitude e orientação conceitual. Portanto, sua prática é promotora de transformações de relações de poder, de práticas e da organização escolar em si, e não de inovações, como costumava acontecer com a administração científica (Lück, 2000, p. 15).

Diante da proposta de se organizar a escola por meio de gestão democrática e participativa, Lück (2000, p. 12) indica que a figura do 
diretor escolar é essencial, dado que “[...] busca permanente pela qualidade e melhoria contínua da educação passa, pois, pela definição de padrões de desempenho e competências de diretores escolares, dentre outros, de modo a nortear e orientar o seu desenvolvimento".

Segundo a referida pesquisadora, duas ópticas definem as competências dos diretores: "[...] a da função/profissão em si e a da pessoa a exercê-la”. As competências relacionadas à função/profissão determinam-se por um “[...] conjunto sistêmico de padrões mínimos necessários para o bom desempenho das responsabilidades que caracterizam determinado tipo de atividade profissional". Por sua vez, as competências relacionadas à pessoa referem-se à sua capacidade de "[...] executar uma ação específica ou dar conta de uma responsabilidade específica”. Isso implica que, para se obter eficiência - por extensão, êxito - no empreendimento, ambas as concepções de competências devem ser consideradas, referindo-se elas a "[...] conhecimentos, habilidades e atitudes referentes ao objeto de ação” (Lück, 2000, p. 14).

Do ponto de vista de Lück (2009), é essencial que se definam os padrões de competências, dado que, por meio de requisitos definidos, torna-se mais acessível o processo de avaliar os profissionais da educação e a eles permitindo seu automonitoramento, ademais se propõe novas estratégias, aprimoramentos que possibilitem a eficiência das práticas cotidianas.

Em síntese, nesta perspectiva, o diretor escolar se apresenta como o profissional responsável pelo funcionamento da escola como um todo, o líder de toda comunidade acadêmica, capaz de colocar em prática, nas escolas, os princípios da gestão democrática, enfim, aquele que busca a eficiência de seus resultados.

Pertinente aos anos 2000, dispõe-se de vasta literatura constituída de coletâneas em que se abona a categoria gestão democrática. Analisam, sobretudo, os limites e as possibilidades de sua consecução nos diferentes Estados e/ou municípios brasileiros (Oliveira, 1997; Luce; Medeiros, 2006; Aguiar; Ferreira, 2004). Os diferentes autores partem das conquistas legais de âmbito nacional (Brasil, 1988; Brasil, 1996), estadual/municipal, e, diversamente do que ocorria em anos anteriores, baseiam-se em leituras da realidade para indicar possíveis caminhos para a escola pública. Neste sentido, há diversidade de produção a respeito da função do diretor de escola, embora a maioria enfatize o coletivo da organização escolar, a tomada de decisão mediante participação efetiva de todos os segmentos e, sobremaneira, a função política do diretor na articulação comunidade-escola.

Em seguida, procede-se a um recorte da legislação publicada entre os anos 1980 e 2000 que, de forma direta ou indireta, indica a função do diretor de escola em âmbito nacional e paulista. Considera-se que, em seu cotidiano, esse profissional da Educação interage com as conquistas teóricas e com as diretrizes da política educacional de todos os 
âmbitos, de modo que, em sua prática e sua concepção, faz reflexo das contradições emanadas desta interação.

\section{Os Documentos Legais e a Função do Diretor de Escola}

Anteriormente à publicação da Constituição Federal (Brasil, 1988) e da Lei de Diretrizes e Bases da Educação Nacional (Brasil, 1996), o Estado de São Paulo promulgou o Estatuto do Magistério Paulista (Lei Complementar n. 444/1985), documento que trata, em suas disposições finais, do Conselho de Escola (CE) como órgão deliberativo da organização escolar. Segundo Pinto (1999, p. 222), sua aprovação em Lei é fruto de negociação na Assembleia Legislativa, uma vez que os diretores se manifestaram contrários, "[...] pais e alunos estiveram ausentes das discussões, e a garantia do caráter deliberativo e composição paritária entre comunidade intra e extraescolar só foi possível em virtude da pressão da entidade representativa dos professores da Associação dos Professores do Ensino Oficial do Estado de São Paulo (APEOESP)". O mesmo autor declara que, à conquista, deve-se acrescentar o fato de André Franco Montoro estar no início de sua gestão no Estado de São Paulo e ter sido eleito graças a propostas de descentralização e democratização da escola, alimentadas, sem dúvida, pelo "[...] clima geral de euforia e participação marcado pela luta por redemocratização, com o ocaso do regime militar", no país (Pinto, 1999, p. 222).

A referida Lei dispõe sobre a composição do CE da seguinte forma: $40 \%$ docentes; $25 \%$ de pais de alunos; $25 \%$ de alunos; $5 \%$ de especialistas (exceto diretor) e $5 \%$ de demais funcionários, devendo ser presidido pelo diretor de escola. O órgão colegiado passa a ter função deliberativa, deve reunir-se, ordinariamente, duas vezes no semestre e, quando necessário, por convocação do diretor ou 1/3 dos seus membros ${ }^{3}$. Diferentes análises cientificam de seus vários avanços importantes: a participação efetiva da comunidade na escola, na tomada de decisão sobre suas diretrizes e metas, projetos, prioridades, elaboração de regimento escolar, apreciação de relatórios e avaliação da escola; a escolha dos membros pelos seus pares; a clareza e transparência das decisões por meio de registros em atas tornadas públicas.

No entanto, alguns autores (Pinto, 1999; Paro, 1999) indicam que, depois de mais de uma década, a Lei não conseguiu alterar a forma de organização da escola pública estadual, em virtude de estar fundamentalmente ancorada na hierarquia e na autoridade do diretor de escola. Deixam transparecer os principais argumentos (dos quais as autoras deste estudo compartilham) que o Conselho de Escola foi uma medida isolada, "[...] descolado de uma política mais ampla e séria de democratização da escola" e que, para a reversão de tal quadro, "[...] é preciso uma nova ética que desautorize a atual configuração autoritária da escola" (Paro, 1999, p. 210). Ademais, enfatiza-se o fato de que não há como cumprir seu papel de indutor da gestão democrática na escola, 
porque "[...] os procedimentos burocráticos que dominam a administração escolar entram em choque direto com aqueles baseados na busca do entendimento por meio do diálogo, como é o caso do CE" (Pinto, 1999, p. 239).

Como é possível perceber, apesar das conquistas legais no sentido de incentivar, na escola, a gestão democrática e a participação da comunidade na tomada de decisão, a organização do trabalho circunscrita na figura do diretor (tal como aquela perspectiva delineada pelos autores entre os anos 1960 e 1970) predomina e triunfa sobre outras concepções.

Nos anos 1990, publicam-se as Normas Regimentais Básicas destinadas às escolas estaduais de São Paulo. Reiteram a presença daquele órgão colegiado e atestam ainda a existência do Conselho de Classe e Série como órgão colegiado e de duas instituições auxiliares de ensino: a Associação de Pais e Mestres e o Grêmio Estudantil. Neste documento (São Paulo, 1998), embora se identifique um Título integral à gestão democrática, presentes os órgãos colegiados e instituições auxiliares de ensino, há também referência à composição detalhada da organização escolar por níveis hierárquicos, cujo primeiro se constitui o núcleo de direção - o diretor e seu vice. $\mathrm{O}$ Título $\mathrm{V}$ do documento respeita à organização técnico-administrativa da escola, declarando que ela “[...] é responsabilidade de cada estabelecimento e deverá constar de seu regimento", além de dever

\begin{abstract}
[...] preservar a flexibilidade necessária para o seu bom funcionamento e estar adequado às características de cada escola, envolvendo a participação de toda comunidade escolar nas tomadas de decisão, no acompanhamento e avaliação do processo educacional (São Paulo, 1998, p. 1042).
\end{abstract}

Não obstante, a seguir no texto do documento, identifica-se como núcleo de direção o “[...] centro executivo do planejamento, organização, coordenação, avaliação e integração de todas as atividades desenvolvidas no âmbito da unidade escolar" (São Paulo, 1998, p. 1043), responsável pelo exercício de várias funções: elaboração e execução da proposta pedagógica, administração do pessoal e dos recursos, cumprimento dos dias letivos, legalidade e autenticidade da vida escolar dos alunos, entre outros.

Independentemente de outras leis publicadas nos anos 1970 e $1980^{4}$, feitas as devidas ressalvas conforme já apontado, os documentos de que se tratou valorizam e incentivam a participação, autonomia e gestão democrática, o que contribui para se vislumbrar uma perspectiva mais afinada com a abordagem progressista de Administração escolar (Paro, 1986; Freire, 1991).

Em meados dos anos 1990, assume o governo do Estado o PSDB, que toma várias medidas por meio da Secretaria do Estado da Educação, entre as quais se destacam a municipalização, a progressão continuada e o SARESP (Sistema de Avaliação do Rendimento da Educação

Educação \& Realidade, Porto Alegre, v. 38, n. 3, p. 977-998, jul./set. 2013

Disponível em: <http://www.ufrgs.br/edu_realidade> 
Função do Diretor na Escola Pública Paulista

do Estado de São Paulo). O Estado paulista emitiu diretrizes para as suas escolas sob o discurso de fortalecer-lhes a autonomia, cuja máxima se encontra na política de Progressão Continuada e suas contradições: uma vez que a repetência foi eliminada no interior dos ciclos, fezse imperativo exercer algum tipo de controle sobre desenvolvimento do processo de aprendizagem dos alunos, ano a ano (SEE, 1996). Adveio a necessidade de monitorar os resultados pedagógicos das escolas e a qualidade de ensino oferecida pelo setor público. Em lugar de construções de práticas de avaliação interna, criou-se o SARESP, com o objetivo de ser um mecanismo de aferição para verificar, nas escolas, os processos pedagógicos frente a essas mudanças.

Um dos documentos do Estado justifica a criação do SARESP como uma resposta à LDBEN (1996), que busca um sistema de ensino unificado para todo o Brasil. Ora, a ausência de equidade sistêmica entre as escolas paulistas urgiu o governo ao estabelecimento de um currículo mínimo para todas as escolas, com a indicação de conhecimentos, competências e habilidades a serem desenvolvidas e avaliadas ao fim de cada ciclo (SEE, 1996).

$\mathrm{O}$ documento não evidencia, no entanto, que essas mudanças curriculares tenham imposto mudanças concretas na organização do trabalho nas escolas, sobremaneira na construção da autonomia das organizações por meio de avaliações internas dos seus processos. Assumidamente de caráter técnico e valorizando aspectos empresariais, a avaliação do SARESP chega às escolas, completando 14 anos em 2011. Acrescenta-se a esses critérios estabelecidos pela Secretaria de Educação do Estado a adoção da política de bonificação aos professores, tendo em vista os resultados atingidos. Além de ser um mecanismo de aferição do trabalho administrativo e pedagógico das unidades, o sistema paulista de avaliação em larga escala configura-se um elemento indutor de políticas públicas educacionais que priorizam a meritocracia e a equidade dos processos escolares face a indicadores estipulados pelo governo.

Em 2008, a SEE determinou que às escolas que ascenderam ao patamar de melhor avaliadas - conforme os critérios de aferição ao longo dos anos de vigência do SARESP - será concedida uma bonificação. Instala-se, pois, uma incoerência: na concepção daquele órgão de ensino, avaliar-se-á o processo, e não apenas a média dos melhores alunos como anteriormente ocorria.

Dada à preocupação com o alcance de resultados de aprendizagem, no bojo dessas medidas publicam-se dois documentos legais: a Resolução SE n. 70/2010 e o Decreto n. 57.141/2011, que tratam, respectivamente, dos perfis profissionais, competências e habilidades requeridos dos educadores da rede pública estadual e da reorganização da Secretaria de Educação do estado de São Paulo. Particularmente, na Seção X, o decreto aborda as atribuições dos diretores de escolas sob a condição de gestores escolares.

988 Educação \& Realidade, Porto Alegre, v. 38, n. 3, p. 977-998, jul./set. 2013 Disponível em: <http://www.ufrgs.br/edu_realidade> 
Os dois documentos causam certo desconforto quando avaliados em confronto com as conquistas legais dos anos 1980, uma vez que neles predomina o uso de termos empresariais, cujo foco incide na hierarquia, sobremaneira na individualização das tarefas da organização do trabalho escolar na figura do diretor (agora tratado como gestor).

Para que o diretor de escola pudesse cumprir os ônus de seu mister, o Governo lhe determinava cinco dimensões de competências, assim discriminadas: de resultados educacionais do processo ensinoaprendizagem; participativa; pedagógica; dos recursos humanos; dos recursos físicos e financeiros.

Contraposto àqueles dos anos 1980, na única vez em que o decreto discorreu a respeito da gestão democrática, o referido documento o faz, porém relacionando-a com “[...] princípios de liderança, mediação e gestão de conflitos” (São Paulo, 2010, p. 97) - aliás, utilizando-se de termos amplamente empregados na Administração empresarial contemporânea. Ademais, quando contempla participação (segunda dimensão), o documento acentua a relevância de o diretor "[...] estimular o estabelecimento de parcerias com vistas à otimização de recursos disponíveis na comunidade" (São Paulo, 2010, p. 100). A sexta competência elencada para o diretor de escola - “[...] compreender a visão contemporânea de gestão escolar vinculada a resultados” (São Paulo, 2010, p. 100) - articula-se bem a esse discurso, na medida em que corrobora a noção de escola equiparada à empresa. De qualquer forma, a análise extensiva do documento legal permite cotejar pontos de afinidade com a perspectiva de Mello (1993) a respeito do novo padrão de gestão, que mescla parcerias, gerenciamento e alcance de certos resultados, com tangências à gestão democrática e participação, mais próximas à perspectiva da gestão de empresas.

O Decreto publicado em 18 de julho de 2011 reorganiza a Secretaria de Educação e estabelece providências correlatas, dedicando os artigos 94 e 106 para atribuir as competências comuns aos chefes de gabinete, dirigentes e diretores de escolar.

Neste sentido, articulados às atividades gerais e às do Sistema de Administração de Pessoal, predominam verbos como cumprir, submeter, encaminhar, zelar, fiscalizar, e substantivos/adjetivos como autoridades superiores, subordinados, superiores, hierárquicos, resultados.

Considerando o exposto, questiona-se: quais as repercussões das diretrizes educacionais no cotidiano escolar? Há possibilidades de vivências democráticas conforme as almejadas em meados dos anos 1980 ? Como os diretores de escolas e os docentes concebem a função do diretor a partir das contradições aqui explicitadas?

Em seguida, proceder-se-á à análise das entrevistas realizadas com estes segmentos - diretores de escola e docentes -, para, nas considerações finais, sugerir novas questões para debate.

Educação \& Realidade, Porto Alegre, v. 38, n. 3, p. 977-998, jul./set. 2013 


\section{Função do Diretor de Escola na Concepção de Diretores e Professores de Escolas Públicas Estaduais de um Município do Interior Paulista}

Perseguindo os objetivos da pesquisa, realizou-se coleta de dados em quatro escolas públicas estaduais de cidade do interior paulista: duas localizadas em bairros periféricos (Escolas 1 e 2) e duas em bairro central (Escolas 3 e 4), em que foram entrevistados três diretoras, um diretor com sua vice e dezesseis professores, quatro em cada escola ${ }^{5}$. As quatro escolas são consideradas de pequeno porte, compostas de trezentos alunos no máximo, uma delas em atividade de tempo integral (Escola 1). Em termos de formação para o exercício da função, pode-se considerar que, em todos os casos, assenta-se ela sobremaneira na experiência acumulada por anos de atuação no magistério e/ou na direção de escolas.

Uma vez realizada a etapa das entrevistas, dois pontos relevantes estimularam a atenção e possibilitaram diagnosticar as percepções dos sujeitos a respeito da função do diretor de escola: como se configura a organização do trabalho na escola e a presença do diretor no espaço escolar. Tomando como referência esses dois elementos, desenvolveuse a extensa e criteriosa análise que permitiu chegar a algumas conclusões, cujos aspectos principais serão brevemente apresentados.

Concernente à forma de organização do trabalho na escola, chamou a atenção o fato de todos os diretores destacarem a divisão de tarefas entre diretor, vice-diretor e coordenador-pedagógico - um aspecto relevante, segundo eles, para a garantia do bom funcionamento da instituição. As diretoras relatam que

[...] a coordenadora é a parte pedagógica. Ela verifica toda a parte pedagógica em relação aos alunos, professor e aluno... É ela quem prepara os pontos-chave. E nós sentamos uma vez por semana ou mais, se for preciso, para fazermos as pautas (D 1,2011).

A vice-diretora trabalha a parte burocrática. A parte do vice é a prestação de contas, leituras de diário oficial, entre outros. Todos os dias sentam diretora e a coordenadora, que cuidam, por exemplo, de recurso para os professores. A diretora acompanha a coordenadora (D 3, 2011).

Outro aspecto comumente declarado nas entrevistas diz respeito à concentração de responsabilidade na pessoa do diretor de escola, o que se evidencia nas seguintes afirmações:

Sou a diretora da escola. Embora a responsabilidade seja minha, se for o coletivo que decide, temos o apoio do coletivo, isto é muito bom. Não vou ficar com o peso sozinha, vou responder sozinha, mas vou repartir as culpas, embora a responsabilidade no final seja minha (D 4, 2011).

Gestão é mais democrática. Antigamente, o diretor era o chefe de tudo. Agora, não é bem assim, embora seja diretora da escola, concursada para isto, sou uma gestora. Lido com seres humanos, não é o que eu penso e, 
sim, o que o grupo quer e pensa. Tenho que acreditar na minha equipe, delego tarefas e estou junto. Minha responsabilidade aumenta muito até, porque tenho estar coordenando tudo isto, mas não dou conta de tudo sozinha, tenho que confiar e deixar o pessoal trabalhar (D 4, 2011).

Nos dois registros, observa-se uma contradição que expressa a ainda incipiente tentativa de vivenciar uma gestão mais participativa que, não raramente, é confundida com a gestão democrática efetiva. $\mathrm{O}$ fato de a diretora considerar importante o que o grupo quer e pensa e os anseios da comunidade, não torna evidente uma prática democrática que culmina em decisão coletiva. Conquanto haja espaço para o diálogo e a confiança mútua - o que se considera imprescindível - o grupo não deixa de ser a equipe $d a$ diretora, por ela coordenada e liderada, e para a qual ela delega tarefas.

A mesma contradição se revela quando se observa - ao menos nas falas das entrevistadas - a existência de Conselhos de Escolas e de Associações de Pais e Mestres (APM), ativos em todas as instituições. Considerados espaços essenciais em instituições que vivenciam a democracia, a presença do Conselho de Escola e da APM não se mostrou eficiente em termos de construção de um espaço coletivo de decisões que pudessem incidir diretamente na organização do trabalho escolar e na formação de sujeitos democráticos.

Uma das diretoras alega que a falta de interesse dos pais provoca a dificuldade de reunir os membros do Conselho e da APM. Ante o impasse, sugere que, para compor esses órgãos, se escolham pais de alunos que sejam funcionários da própria escola, ou, conforme declarou a diretora, mães que tenham um pouco mais de esclarecimento, portanto apresentam melhor condição de participar das reuniões e dar seus palpites. Acredita-se que essa alternativa de solução ao empecilho não se restrinja a apenas essa escola: estende-se pelas demais.

Outro ponto mencionado pelos diretores diz respeito à cobrança da Diretoria de Ensino, efetivada sobremaneira no alcance de resultados nas avaliações externas. Isso lhes vem subtrair ainda mais do restrito tempo que resta para organizar o trabalho pedagógico e as oportunidades coletivas de diálogo, participação e decisão.

Embora possa parecer um subterfúgio para a ausência de uma organização efetiva de colegiados na escola, esse aspecto confirma o que se indicou na análise dos documentos oficiais: demonstra haver, por parte do órgão central (Estado), uma cobrança de responsabilidade centralizada na figura do diretor de escola. Essa análise tangencia sobremaneira a perspectiva de Mello (1993), já desenvolvida anteriormente.

Nesses termos, as bases de organização do trabalho na escola se aproximam da crítica efetuada por Paro (1986), em que é possível visualizar o diretor como preposto do Estado - o responsável por atingir objetivos formulados fora e acima da escola, inclusive no que respeita

Educação \& Realidade, Porto Alegre, v. 38, n. 3, p. 977-998, jul./set. 2013.

Disponível em: <http://www.ufrgs.br/edu_realidade> 
à exigência de se instituir uma gestão democrática. Como se isso fosse possível da noite para o dia... A conjuntura apresentada justifica a prevalência de um discurso que, enquanto preza a democracia, também torna explícita a função do diretor de escola como cumpridor de tarefas previamente determinadas. $\mathrm{O}$ fato detectado vem ao encontro das contradições expressas quando do exame aos documentos legais, de modo que os diretores se veem confinados entre as possibilidades de exercício da democracia no interior da escola e a necessidade de prestação de contas do desenvolvimento de suas competências e habilidades, estabelecidas também pelo governo do Estado.

Delineia-se, dessa maneira, a imagem do diretor como líder institucional, aquele que rege a orquestra com competência, tomando todo o cuidado necessário para que todos dancem conforme a música. A esse respeito, afirmou a vice-diretora:

[...] é uma orquestra, nós temos que funcionar como uma orquestra. O diretor tem que ter... ser muito vivo, mesmo. E ele tem que saber escolher as pessoas com quem ele trabalha, as pessoas que pode confiar. Que é um trabalho de confiança, também. Porque, além de todos os professores, a parte da secretaria... e ele tem a família, a comunidade e tudo isso aqui para dar conta. Acho que tem que conhecer muito bem o aluno que tem não só o nome, saber tudo que está por trás (VD 2, 2011).

Você tem que abrir as coisas para o grupo, mas, em determinadas decisões, por exemplo, a digitação de notas tem um tempo delimitado, tenho que marcar prazo para a entrega de notas. Na educação, como em qualquer lugar, tem de haver cobrança, senão, a coisa desanda. Fazemos reunião, questiono qual o melhor prazo, os professores opinam e aí delimitamos o dia. Eu abro para o grupo, mas a decisão, o controle é do líder. Nem tudo pode, a escola tem regras discutíveis, mas elas têm de ser cumpridas depois de estabelecidas. Muitas coisas já são pré-determinadas, não há como discutir, aí é necessário cumprir (D 3, 2011, grifos nossos).

O discurso estabelece algumas relações com a abordagem de Alonso (1976), acerca do papel do diretor na administração escolar e, mais recentemente, do tratamento dispensado à liderança da escola por outros estudiosos, como Thurler (2001) e Lück (1998), que abordam, inclusive, suas fontes. Nesse caso, evidencia-se o que a primeira autora denomina o estatuto de autoridade, ou seja, a função do diretor como atividade superior, frequentemente se sobrepondo às demais, componentes da organização escolar.

Na concepção da diretora entrevistada, a escola se configura uma grande família, o que remete à abordagem de Lourenço Filho (1963), em que o exercício da liderança é visto como a capacidade do administrador em bem interpretar o "[...] espírito comum da organização, optando e decidindo no melhor sentido de sua coesão" (Lourenço Filho, 2007, p. 78).

É curioso perceber que a mesma visão é compartilhada por professores. Quando entrevistados, consideraram competência do diretor 
a de conduzir e organizar a escola. Bom diretor é o líder que toma a frente, que tem um objetivo a cumprir e consegue. Não demonstraram se importar com que esses objetivos sejam alcançados de forma persuasiva ou democrática.

Segundo entendem as professoras, o diretor - um líder democrático - é aquele que ouve. Embora não possa acatar tudo, por estar submetido às imposições da Diretoria, antes de apresentar e fazer cumprir as ordens advindas de instâncias superiores, ele dialoga, comunica, aceita as opiniões, acalmando os ânimos e estabelecendo um clima igualmente democrático.

Para dois professores, o diretor-líder é aquele que procura desenvolver democracia relativa. Conquanto tenham declarado que, em suas escolas, procura-se desenvolver a democracia mediante decisão compartilhada, o que se enfatizou anteriormente a respeito da autoridade do diretor e de sua subserviência a instâncias superiores mais uma vez se confirma:

Eu vejo a diretora, a vice-diretora, a coordenadora, a chefia da escola que busca fazer em conjunto [...] mas, quem aprova ou não as decisões, é a diretora. Se ela não aprovar alguma coisa, ela... Tem que ceder, mesmo que a escola inteira fique ao contrário. Ela geralmente não faz isso, mas se ela quiser, ela pode fazer isso. E isso acontece, às vezes (P 3, 2011).

[...] é passado para ele lá de cima e depois é passado para nós pormos em prática dentro da sala de aula. Porque não é só propormos. Tem coisa que vem lá de cima. Como agora, o 'Ler e Escrever'. É uma cobrança porque vem lá de cima e a gente é cobrada dentro da sala de aula, e não só cobrado, vem visita dentro da sala de aula pra ver se o professor está fazendo aquilo ou não está fazendo (P 4, 2011).

$\mathrm{Na}$ escola 4, as opiniões dos professores coincidiram com as dos demais. No entanto, três deles admitiram a presença de outras lideranças; por exemplo, de professores mais velhos que sabem aconselhar e dar suporte quando necessário. Os professores também deixaram transparecer que, nessa escola, a gestão é democrática, tomada no sentido já exposto anteriormente, ou seja, em que as opiniões podem ser expressas irrestritamente, embora nem sempre possam ser transformadas em prática.

Considerando os autores que abordaram a função do diretor na escola, pode-se dizer que a análise da percepção dos professores, independente de suas especificidades, vai ao encontro de elementos trabalhados por vários autores em diferentes tempos históricos, sobremaneira daqueles que apresentam uma visão sistêmica da organização escolar e defendem a função do diretor como líder institucional. Assim o fazem Alonso (1976); Lourenço Filho (1963); Lück (2000) e Thurler (2001).

Importa esclarecer que os discursos se distanciam muito da perspectiva teórica de Paro (1986), convergem, não obstante, para suas críticas em relação ao autoritarismo do sistema escolar e do excesso de regulamentação exterior.

Educação \& Realidade, Porto Alegre, v. 38, n. 3, p. 977-998, jul./set. 2013.

Disponível em: <http://www.ufrgs.br/edu_realidade> 


\section{Considerações Finais}

O objetivo deste estudo constituiu-se da análise da função do diretor de escola pública estadual, sustentada pela percepção dos fatos em três âmbitos: dos profissionais, de documentos legais e de autores clássicos da Administração Escolar. Partiu-se da hipótese de que os profissionais da educação percebem a função do diretor e a vivenciam por meio das tensões estabelecidas entre a realidade da escola pública, a produção do conhecimento e as diretrizes da política educacional.

A incursão nas ideias mais relevantes de alguns autores considerados clássicos na área favoreceu detectar, entre os anos 1960 e 1970, a predominância da Administração de Empresas como subsídio teórico da Administração Escolar, como já diagnosticado por outros autores (Paro, 1986; Russo, 2004). Concebeu-se o diretor como executivo na unidade escolar, líder no sentido de motivar o alcance de objetivos postos fora e acima de sua escola, e autoridade hierarquicamente constituída e responsável pelo progresso da empresa escolar. Nos anos 1980, houve preocupação de descentrar o diretor no exercício de sua função, experimentando novos subsídios teóricos para a Administração Escolar que permitissem pensar sua própria natureza. Na literatura específica da área, produzida nesta década, percebem-se termos completamente distintos dos anteriores, sobremaneira os que se referem à participação, ao tratamento ao coletivo e à gestão democrática. Nos anos 1990, identifica-se a convivência de diferentes perspectivas teóricas e metodológicas, a predominância de coletâneas, abordagens que se aproximam da gestão empresarial e perspectivas afinadas com as ideias dos anos 1980. Ademais, vale registrar que, em uma mesma abordagem, percebem-se aspectos que, evidentemente, parecem inconciliáveis. Por exemplo, é o caso da expressão liderança para uma gestão democrática.

Os documentos legais analisados ensejaram inferências bastante semelhantes, por explicitarem, nos anos 1980, conquistas democráticas no momento de redemocratização do País e, por extensão, do Estado de São Paulo, entre as quais figura o incentivo à participação na escola, mediante a instituição de Conselhos escolares. Já nos anos 1990, sobremaneira nos anos 2000, os documentos legais (agora não mais Estatutos ou Normas, mas Decreto e Resolução) especificam e evidenciam a função do diretor como executivo da escola, responsável por seus resultados. Neste momento, a definição da função é revestida de termos comumente utilizados na literatura sobre Administração empresarial e que atualmente se apresenta com certa frequência no campo da gestão educacional.

Os profissionais da educação entrevistados deixam transparecer esta tensão, mesmo que não o façam de forma consciente. Considera-se tensão, porque, de um lado, há conquistas teóricas e legais que indicam possibilidades de vivências democráticas; de outro, porque a Administração/gestão escolar não conseguiu teoricamente contrapor-se aos

994 Educação \& Realidade, Porto Alegre, v. 38, n. 3, p. 977-998, jul./set. 2013. Disponível em: <http://www.ufrgs.br/edu_realidade> 
ditames empresariais. Do ponto de vista das diretrizes políticas aqui analisadas, tornadas conhecidas pela publicação de documentos legais que ao definirem pormenorizadamente as competências, habilidades $\mathrm{e}$ atribuições do diretor de escola, cobram-lhe o compromisso de concretizá-las, em busca de resultados fixos externamente às escolas.

No registro e documentação das diferentes execuções discursivas dos entrevistados, pôde-se observar que transitam por termos que, tal como por eles articulados, beiram à incoerência, à incompatibilidade. Trata-se de um ir e vir de ideias de o diretor poder, mas não poder ao mesmo tempo; de existir, de fato, participação, mas tomada na noção de poder falar e ser ouvido, e não no sentido de participar efetivamente da tomada de decisão.

As ideias aqui desenvolvidas são bastante significativas no sentido de revisão de algumas certezas declaradas tanto por profissionais da escola básica como por colegas da universidade, a principal delas é a de que os profissionais da escola não querem e não sabem participar, ou que o diretor (a) de escola é autoritário e não quer repartir o poder. Podemos considerar, após a análise, que suas percepções e vivências são construídas a partir dos (des)entendimentos das diretrizes da política e do (des)conhecimento da produção científica, com suas falhas e conquistas. E, neste sentido, resta-nos uma questão: qual o papel da universidade para além da crítica da política e/ou da escola pública?

Recebido em 12 abril de 2012 Aprovado em 22 de agosto de 2012

\section{Notas}

1 Utilizou-se de edição mais recente do livro do autor, mas importa considerar que sua primeira publicação data de 1963.

2 Ver mais em Maia (2008).

3 Segundo Pinto (1999), o Conselho de Escola (CE) tem sua origem nas antigas congregações reguladas pelo Decreto n. 22.036/53 que foram substituídas pelos Conselhos de Professores (Decreto n. 45. 159/65). O autor acrescenta que o Conselho de Escola de caráter consultivo data do regimento comum das escolas estaduais (Decreto n. 10.623/77); transformou-se em órgão deliberativo pela promulgação da Lei Complementar n. 375/1884. A Lei Complementar n. $444 / 1985$ prescreveu sua forma atual.

4 Boccia (2010) faz interessante pesquisa de mestrado com o objetivo de analisar o papel do diretor de escola na rede pública estadual de São Paulo na legislação e na prática e identifica as seguintes Leis denominadas por ela de "funcionais" (entre os anos 1960 e 1980): Lei 10.261/68 - Estatuto dos funcionários públicos civis do estado de São Paulo; Decreto 7.510/76 - reorganiza a Secretaria de estado da educação; Decreto 17.329/81 - define a estrutura e as atribuições de órgãos e as competências das autoridades da Secretaria de Educação em relação ao sistema de administração de pessoal.

Educação \& Realidade, Porto Alegre, v. 38, n. 3, p. 977-998, jul./set. 2013.

Disponível em: <http://www.ufrgs.br/edu_realidade> 
5 Os entrevistados serão assim denominados: Diretor da escola 1 (D 1), Diretor da escola 2 (D 2), assim por diante. Quanto aos professores, identificar-se-á: P 1, P 2 etc.

\section{Referências}

AGUIAR, Márcia Ângela da Silva; FERREIRA, Naura Syria Carapeto. Gestão da Educação: impasses, perspectivas e compromissos. 4. ed. São Paulo: Cortez, 2004.

ALONSO, Myrtes. O Papel do Diretor na Administração Escolar. São Paulo: Difel, 1976 .

ALVES, Nilda; GARCIA, Regina Leite. A Necessidade da Orientação Coletiva nos Estudos sobre o Cotidiano: duas experiências. Revista Portuguesa de Educação, Universidade do Minho, Braga, v. 14, n. 02, p. 1-37, 2001.

BOCCIA, Margarete Bertolo. O Papel do Diretor de Escola na Rede Pública Estadual de São Paulo: da legislação à prática. 2008. 169 p. Dissertação (Mestrado em Educação) - Programa de Pós-Graduação em Educação, Universidade Nove de Julho, São Paulo, 2008.

BRASIL. Constituição da República Federativa do Brasil de 1988. Disponível em: <http://www.planalto.gov.br/ccivil_03/Constituicao/Constituicao.htm>. Acesso em: 09 mar. 2012.

BRASIL. Lei n. 9.394, de 20 de dezembro de 1996. Portal do Ministério da Educação. Disponível em: <http://www.planalto.gov.br/ccivil_03/Leis/L9394.htm>. Acesso em: 09 mar. 2012.

CANÁRIO, Rui. O Estudo Sobre a Escola: problemas e perspectivas. In: BARROSO, João (Org.). O Estudo da Escola. Portugal: Porto Editora, 1996.

FONSECA, Marília. O Banco Mundial e a Gestão da Educação Brasileira. In: OLIVEIRA, Dalila Andrade (Org.). Gestão Democrática da Educação. Petrópolis: Vozes, 1997.

FREIRE, Paulo. A Educação na Cidade. 7. ed. São Paulo: Cortez, 1991.

KRAWCZYK, Nora. Em Busca de uma Nova Governabilidade na Educação. In: OLIVEIRA, Dalila Andrade (Org.). Política e Gestão da Educação. 2. ed. Belo Horizonte: Autêntica, 2008.

LIMA, Márcia Regina Canhoto de. Paulo Freire e a Administração Escolar: a busca de um sentido. Brasília: Líber Editora, 2007.

LOURENÇO FILHO, Manuel Bergström. Organização e Administração Escolar: curso básico. 8. ed. Rio de Janeiro: Instituto de Estudos e Pesquisas educacionais Anísio Teixeira, 2007.

LUCE, Maria Beatriz; MEDEIROS, Isabel Letícia Pedroso de. Gestão Democrática da Escola Pública: práticas e vivências. Porto Alegre: Editora da UFRGS, 2006.

LÜCK, Heloísa. Dimensões de Gestão Escolar e suas Competências. Curitiba: Editora Positivo, 2009.

LÜCK, Heloísa. Escola Participativa: o trabalho do gestor escolar. São Paulo: DP\&A, 2000

LÜCK, Heloísa. Gestão Participativa: o trabalho do gestor escolar. Rio de Janeiro: DP\&A, 1998.

MAIA, Graziela Zambão Abdian. As Publicações da ANPAE e a Trajetória do

996 Educação \& Realidade, Porto Alegre, v. 38, n. 3, p. 977-998, jul./set. 2013

Disponível em: <http://www.ufrgs.br/edu_realidade> 
Conhecimento em Administração da Educação no Brasil. Revista Brasileira de Política e Administração da Educação, Recife, v. 24, n. 1, p. 31-50, 2008.

MELLO, Guiomar Namo de. Cidadania e Competitividade: desafios educacionais do terceiro milênio. São Paulo: Cortez, 1993.

NÓVOA, Antônio. As Organizações Escolares em Análise. Lisboa: Publicações Dom Quixote, 1995.

OLIVEIRA, Cleiton de. Gestão da Educação: união, Estado/DF, município e escola. In: MACHADO, Lourdes Marcelino; FERREIRA, Naura Syria Carapeto. Política e Gestão da Educação: dois olhares. Rio de Janeiro: DP\&A, 2002. (Biblioteca ANPAE).

PARO, Vitor Henrique. Administração Escolar: introdução crítica. São Paulo: Cortez: Autores Associados, 1986.

PARO, Vitor Henrique. O Conselho de Escola na Democratização da Gestão Democrática. In: BICUDO, Maria Aparecida Viggiani; SILVA JR., Celestino Alves da (Org.). Formação do Educador: organização da escola e do trabalho pedagógico. São Paulo: Editora UNESP, 1999. P. 209-218. (Seminários \& Debates; v. 3).

PINTO, José Marcelino de Rezende. O Paradoxo do Conselho de Escola. In: BICUDO, Maria Aparecida Viggiani; SILVA JR., Celestino Alves da (Org.). Formação do Educador: organização da escola e do trabalho pedagógico. São Paulo: Editora UNESP, 1999. P. 219-248. (Seminários \& Debates; v. 3).

RIBEIRO, José Querino. Introdução à Administração Escolar: alguns pontos de vista. Cadernos de Administração Escolar, Salvador, n. 2, 1968.

RUSSO, Miguel Henrique. Escola e Paradigmas de Gestão. EccoS: revista científica, São Paulo, v. 6, n. 1, p. 25-42, 2004.

SÃO PAULO. Resolução SE n. 27, de 29 de março de 1996. Dispõe sobre o Sistema de Avaliação de Rendimento Escolar do Estado de São Paulo. São Paulo: 1996. Disponível em: <http://lise.edunet.sp.gov.br/paglei/resolucoes/27_1996. htm> Acesso em: 09 mar. 2012.

SÃO PAULO. Parecer CEE n. 67/98 - CEF/CEM, aprovado em 18 de março de 1998. Normas Regimentais Básicas para as escolas estaduais. São Paulo: 1998. Disponível em: <www.crmariocovas.sp.gov.br/pdf/diretrizes_pl022-1048_c. pdf $>$. Acesso em: 09 mar. 2012.

SÃO PAULO. Resolução SE 70, de 26 de outubro de 2010. Dispões sobre os perfis profissionais, competências e habilidades requeridos dos educadores da rede pública estadual e os referenciais bibliográficos que fundamentam os exames, concursos e processos seletivos, e dá providências correlatas. Disponível em: <www.saiu.edunet.sp.gov.br/itemlise/arquivos/RESOLUÇÃO\%20SE\%20No\%20 70_10.HTM>. Acesso em: 09 mar. 2012.

TEIXEIRA, Anísio. Natureza e Função da Administração Escolar. In: Administração Escolar: Edição comemorativa do I SIMPÓSIO INTERAMERICANO DE ADMINISTRAÇÃO ESCOLAR, Edição comemorativa, 1., 1968, Salvador. Anais... Salvador: ANPAE, 1968. P. 1-47.

TEIXEIRA, Anísio. Educação para a Democracia: introdução à Administração Escolar. Ed. rev. e coment. Rio de Janeiro: UFRJ, 1997.

THURLER, Monica Gather. Inovar no Interior da Escola. Porto Alegre: Artmed Editora, 2001

Educação \& Realidade, Porto Alegre, v. 38, n. 3, p. 977-998, jul./set. 2013

Disponível em: <http://www.ufrgs.br/edu_realidade> 
Graziela Zambão Abdian é professora assistente doutora do Departamento de Administração e Supervisão Escolar e do Programa de Pós Graduação em Educação da Faculdade de Filosofia e Ciências (UNESP/Marília). Líder do Centro de Estudos e Pesquisas em Administração da Educação - CEPAE, coordenadora de subprojeto pertencente à pesquisa do Observatório de Educação CAPES/INEP, Edital n. 38/2010.

E-mail: graziela.maia@gmail.com

Maria Eliza Nogueira Oliveira é doutoranda do Programa de Pós-Graduação em Educação da UNESP Marília. Graduada em Pedagogia e mestre em Educação pela Faculdade de Filosofia e Ciências (UNESP/Marília). Integra o Centro de Estudos e Pesquisas em Administração da Educação (CEPAE), cujas pesquisas são direcionadas para as áreas de gestão educacional, formação do pedagogo e políticas públicas para e educação. Bolsista do Observatório de Educação CAPESP/INEP, Edital n. 38/2010.

E-mail: mariaeliza_oliveira@hotmail.com

Graziela de Jesus é professora do ensino fundamental da Secretaria Municipal de Educação de Marília/SP. Graduada em Pedagogia pela Faculdade de Filosofia e Ciências de Marília (UNESP/Marília) e mestranda em Educação pelo Programa de Pós Graduação da mesma instituição. Integra o Centro de Estudos e Pesquisas em Administração da Educação - CEPAE. Bolsista do Observatório de Educação CAPES/INEP, Edital n. 38/2010.

E-mail: grazieladejesus@hotmail.com 